\title{
Geographical variation and associated factors of childhood measles vaccination in Ethiopia: a spatial and multilevel analysis
}

\author{
Tesfahun Taddege Geremew ${ }^{1,2^{*}}$ (D) Lemma Derseh Gezie ${ }^{3}$ and Ayenew Negesse Abejie $e^{4,5}$
}

\begin{abstract}
Background: In Ethiopia, despite considerable improvement of measles vaccination, measles outbreaks is occurring in most parts of the country. Understanding the neighborhood variation in childhood measles vaccination is crucial for evidence-based decision-making. However, the spatial pattern of measles-containing vaccine (MCV1) and its predictors are poorly understood. Hence, this study aimed to explore the spatial pattern and associated factors of childhood MCV1 coverage.

Methods: An in-depth analysis of the 2016 Ethiopia demographic and health survey data was conducted, and a total of 3722 children nested in 611 enumeration areas were included in the analysis. Global Moran's I statistic and Poisson-based purely spatial scan statistics were employed to explore spatial patterns and detect spatial clusters of childhood MCV1, respectively. Multilevel logistic regression models were fitted to identify factors associated with childhood MCV1.
\end{abstract}

Results: Spatial hetrogeniety of childhood MCV1 was observed (Global Moran's I = 0.13, $p$-value $<0.0001$ ), and seven significant SaTScan clusters of areas with low MCV1 coverage were detected. The most likely primary SaTScan cluster was detected in the Afar Region, secondary cluster in Somali Region, and tertiary cluster in Gambella Region. In the final model of the multilevel analysis, individual and community level factors accounted for $82 \%$ of the variance in the odds of $\mathrm{MCV} 1$ vaccination. Child age ( $A O R=1.53 ; 95 \% \mathrm{Cl}: 1.25-1.88$ ), pentavalent vaccination first dose (AOR $=9.09 ; 95 \% \mathrm{Cl}: 6.86-12.03)$ and third dose ( $\mathrm{AOR}=7.12 ; 95 \% \mathrm{Cl}: 5.51-9.18$, secondary and above maternal education ( $A O R=1.62 ; 95 \% \mathrm{Cl}: 1.03-2.55$ ) and media exposure were the factors that increased the odds of MCV1 vaccination at the individual level. Children with older maternal age had lower odds of receiving MCV1. Living in Afar, Oromia, Somali, Gambella and Harari regions were factors associated with lower odds of MCV1 from the community-level factors. Children far from health facilities had higher odds of receiving MCV1 (AOR $=1.31,95 \% \mathrm{Cl}=$ 1.12-1.61).

Conclusion: A clustered pattern of areas with low childhood MCV1 coverage was observed in Ethiopia. Both individual and community level factors were significant predictors of childhood MCV1. Hence, it is good to give priority for the areas with low childhood MCV1 coverage, and to consider the identified factors for vaccination interventions.

Keywords: Measles, Vaccination, Spatial, Multilevel, Ethiopia

\footnotetext{
* Correspondence: tesfahun.taddege@yahoo.com

'Ethiopian Field Epidemiology and Laboratory Training Program, Department

of Epidemiology and Biostatistics, Institute of Public Health, College of

Medicine and Health Sciences, University of Gondar, P.O. Box 169, Gondar,

Ethiopia

${ }^{2}$ Department of Reproductive Health and Population Studies, School of

Public Health, College of Medicine and Health Sciences, Bahir Dar University,

P.O. Box 79, Bahir Dar, Ethiopia

Full list of author information is available at the end of the article
}

(c) The Author(s). 2019 Open Access This article is distributed under the terms of the Creative Commons Attribution 4.0 International License (http://creativecommons.org/licenses/by/4.0/), which permits unrestricted use, distribution, and reproduction in any medium, provided you give appropriate credit to the original author(s) and the source, provide a link to the Creative Commons license, and indicate if changes were made. The Creative Commons Public Domain Dedication waiver (http://creativecommons.org/publicdomain/zero/1.0/) applies to the data made available in this article, unless otherwise stated. 


\section{Background}

Measles is a very contagious respiratory disease caused by measles virus and spreads through respiratory droplets when an infected person coughs or sneezes [1]. It is a vaccine preventable disease that can cause serious illness, lifelong complications and death. In 2014, it was estimated that 114,900 deaths due to measles had occurred globally, of which 73, 914 deaths (93\%) were occurred in Africa [2, 3]. Before starting measles vaccination program, nearly $90 \%$ of children aged under-15 years were infected with measles $[4,5]$. In the era of expanded immunization program, the global measles deaths declined by three-fourth from 2000 to $2014[2,6,7]$, but measles is still considered as a public health emergency that requires immediate notification and rapid public health response [5]. World Health Organization (WHO) has targeted a global elimination of measles to reduce annual incidence rates (IRs) to less than five cases per million population, which requires more than $90 \%$ coverage of at least one dose of Measles-Containing Vaccine (MCV1) by the end of 2015 and more than $95 \%$ coverage by 2020 in all countries [5]. In 2015, MCV1 coverage had reached $85 \%$ globally, and the measles deaths declined by $79 \%$ as compared to 2000 [4]. However, the 2015 measles vaccination goal was not met and measles IR remained relatively unchanged between 2013 and 2014 [2].

Ethiopia accounted for $3.4 \%$ of the estimated 20.8 million infants globally who did not receive MCV1 through routine immunization services in 2015 [8], and 9\% of the global measles mortality is attributed to Ethiopia $[6,9]$. In Ethiopia, childhood immunization coverage is improved through the combine effect of Reaching Every District (RED) approach, health extension program and implementation of Enhanced Routine Immunization Activities (ERIAs) [7, 10-12]. It is expected that measles immunization coverage should have an inverse relation with the of the incidence rate of measles [13]. However, despite a considerable improvement of childhood MCV1 in Ethiopia, measles outbreaks are occurring continuously in most parts of the country. As the MCV1 coverage increased from $59 \%$ in 2005 to $84 \%$ in $2014[4,7,9,11,14]$, the incidence rate of confirmed measles cases per 100,000 population increased from 0.6 in 2005 to 11.2 in 2014 [11]. This continuous occurrence of measles outbreak irrespective of measles vaccination could be attributed to spatial heterogeneity of measles vaccination $[5,11]$.

Spatial heterogeneity of measles vaccination coverage can delay measles elimination even in countries with high average nationwide vaccination coverages $[15,16]$.

Understanding the neighborhood variation in measles vaccination is crucial for evidence-based decision-making in meales perevention and control program and detecting spatial heterogeneity is useful to identify gaps in the performance of measles immunization programme that could not be identified through the routine monitoring of vaccination coverage [5]. However, studies are limited on the spatial pattern of childhood MCV1 and its associated factors in Ethiopia. Hence, this study aimed to explore the spatial pattern of MCV1 and associated factors among children.

\section{Methods \\ Study settings}

The Ethiopia demographic and health survey (EDHS) is a national and subnational representative household survey, which is conducted every 5 year. Ethiopia is second most populous country in Africa, located in the horn of Africa. Administratively, Ethiopia is sub-divided into 11 geographical regions; each region is again sub-divided into zones, and zones into districts. The districts in-further are sub-divided into kebeles (the smallest administrative units). During the 2007 Ethiopian population and housing census, each kebele was sub-divided into enumeration areas (EAs), which were used as a sampling frame for the 2016 EDHS.

The health system of Ethiopia, which focuses on a preventive health care, is organized into three-health tire system: Primary health care unit (PHCU), general hospital and specialized hospital. Routine child immunization is primarily provided at PHCUs through static and outreach sites [17], and the availability of routine childhood vaccination services including measles vaccine in Ethiopia is 80\% [18].

\section{Study population and eligibility}

Children aged 12-35 months living in the selected EAs were the study population. All children aged 12-35 months were included and children whose geographical locations were not available at the global positioning system (GPS) were excluded from this study. Hence, a total of 23 EAs, which consisted 133 children, were excluded from the analysis.

\section{Sampling technique and sample size}

The 2016 EDHS used a stratified, two-stage cluster sampling design using the enumeration areas (EAs) of the 2007 Ethiopian population and housing census (PHC) as the primary sampling unit (PSU) and households as the secondary sampling unit (SSU). In the first stage, 645 EAs (202 in urban areas and 443 in rural areas) were selected with probability proportional to EAs size (PPS) from the complete list of 84,915 EAs created for the 2007 PHC sampling frame. In the second stage of selection, a fixed number of 28 households per cluster were selected with an equal probability systematic selection from the newly created household listing. Finally, 16,650 households were successfully interviewed, yielding a response rate of $98 \%$. A total of 3722 children aged 12-35 months nested in 611 EAs were included in this analysis. 
The detailed methodology has been published in the 2016 EDHS final report [19].

\section{Data source and extraction}

The 2016 Ethiopia demographic and health survey datasets, which are publicly available to all registered users, were requested and downloaded from Measure DHS program website (https://www.dhsprogram.com/data/ dataset_admin). Childhood MCV1 status and its potential predictor variables at individual and community level were extracted accordingly.

\section{Study variables}

\section{Dependent variables}

MCV1 vaccination status of the last child aged 12-35 months was the outcome variable of this study. If the child had received MCV1, it was classified as "Yes", otherwise "No", and the data was collected from written vaccination records (including the infant immunization card and other health cards), and mothers' verbal reports.

\section{Independent variables}

Both individual and community level characteristics were considered as potential the potential predictor variables for MCV1. Table 1 depicted the potential predictor variables included in this study along with their categories. Individual-level (level I) variables include sociodemographic and economic characteristics, while community-level (level II) variables include the common characteristics of study subjects in an enumeration area such as region and place of residence.

\section{Operational definitions}

Clustering: An unusual aggregation of children with the same MCV1 status (vaccinated or unvaccinated) in a specific geographical area $[20,21]$.

Measles-containing vaccines (MCV): Vaccines containing antigens of measles only $(\mathrm{M})$ or a combination of measles with rubella (MR), mumps (MM, MMR) and varicella (MMRV) vaccines [22].

Children who received MCV1: Children who received a one dose measles-containing vaccine for the first time at any time before the survey (based on the evidence

Table 1 Independent variables and categorization

\begin{tabular}{|c|c|}
\hline Variables & Categories \\
\hline \multicolumn{2}{|l|}{ 1. Individual level factors (level I) } \\
\hline \multicolumn{2}{|l|}{ Child characteristics } \\
\hline Age of child (months) & (1) 12-23; (2) 24-35 \\
\hline Sex of the child & (1) Male; (2) Female \\
\hline Birth order & (1) 1 ; (2) 2-3; (3) 4-5; (4) 6+ \\
\hline Acceptance of the child & (1) Wanted then, (2) Wanted later \& (3) Wanted no more \\
\hline DPT1-HepB1-Hib1 & (0) Not vaccinated; (1) Vaccinated \\
\hline DPT3-HepB3-Hib3 & 0) Not vaccinated; (1) Vaccinated \\
\hline \multicolumn{2}{|l|}{ Maternal/paternal characteristics } \\
\hline Mother's age (years) & (1)15-19; (2) 20-34; (2) 35-49 \\
\hline Religion & (1)Orthodox; (2)Muslim; (3)Protestant; (4) Others \\
\hline Mother's education & (1) No education; (2)Primary; (3) Secondary and higher \\
\hline Father's education & 1) No education; (2)Primary; (3) Secondary and higher \\
\hline Wealth index & (1) Poorest; (2)Poorer; (3) Rich; (4) Richer; (5)Richest \\
\hline Sex of household head & (1) Male; (2) Female \\
\hline Number of living children & (1) 1 ; (2) 2-3; (3) 4-5; (4) 6+ \\
\hline Head of household & (1) Male; (2) Female \\
\hline $\begin{array}{l}\text { Mother's relation to the head of } \\
\text { the household }\end{array}$ & (1) Wife; (2) head; (3)Daughter; (4) Others \\
\hline Regular media exposure & (0) No; (1) Yes \\
\hline \multicolumn{2}{|l|}{ 2. Community level factors (Level II) } \\
\hline Residence & (1) Urban; (2) Rural \\
\hline Region & $\begin{array}{l}\text { (1) Addis Ababa; (2)Tigray; (3) Afar; (4) Amhara; (5) Oromiya; (6) Somali; (7) Benishangul-Gumuz; (8) SNNPR; (9) } \\
\text { Gambella; (10) Harari; (11) Dire Dawa }\end{array}$ \\
\hline Distance to health facility & (1) A big problem, (2) Not a big problem \\
\hline
\end{tabular}


from vaccination cards, health facility records, or the mother's report) [19].

Exposure to mass media: Women were asked how often they read a newspaper, listened to the radio, or watched television per week. Those who responded at least once a week are considered to be regularly exposed to that form of media [19].

\section{Data management and statistical analysis}

We re-categorized children's age, mother's age, birth order, mother's educational status, religion, number of under-five children, and mother's relation to the head of the household to better suit with other studies for comparison. We used SaTScan 9.6 (https://www.satscan.org/ ) [23] and ArcGIS version 10.3 (http://www.esri.com/) for spatial analysis, and Stata version 14 (https://www. stata.com/) [24] for non-spatial statistical analysis.

Sample weights were applied to compensate for the unequal probability of selection between the strata that has been geographically defined. The detailed explanation of the weighting procedure can be found in the methodology of the EDHS final report [19].

Spatial Analysis: The aggregated MCV1 count data was joined to the geographic coordinates based on each EA unique identification code. To evaluate whether the pattern expressed is clustered, dispersed, or random across the study areas, global spatial autocorrelation was assessed with ArcGIS using the Global Moran's I statistic (Moran's I) [25]. When $p$-value indicates statistical significance, a positive Moran's I index value indicates tendency toward clustering while a negative Moran's I index value indicates tendency toward dispersion [25].

In the presence of positive global spatial autocorrelation, we employed Kulldorffs method of purely spatial scan statistic using the discrete Poisson probability model in SaTScan to detect the local spatial clusters of areas with high or low childhood MCV1 coverages. "SaTScan ${ }^{\mathrm{Tw}}$ is a trademark of Martin Kulldorff, and a software which was developed under the joint auspices of (i) Martin Kulldorff, (ii) the National Cancer Institute, and (iii) Farzad Mostashari of the New York City Department of Health and Mental Hygiene" $[21,23,26]$. SaTScan uses a circular window that moves systematically throughout the study area to identify statistically significant SaTScan clustering of areas with the same childhood MCV1 coverage. We used a maximum of $10 \%$ (to avoid the detection of large clusters) of the population at risk for the spatial cluster size and the analysis was done using standard Monte Carlo hypothesis testing with 999 Monte Carlo replicates. A cluster is statistically significant when its log likelihood ratio (LLR) is greater than the Standard Monte Carlo critical value (C.V) for 0.05 significance level or $p$-value $<0.05[21,23]$.

Multilevel logistic regression Analysis: The data of this analysis included 3722 children nested within 611 EAs.
Hence, considering the hierarchical nature of the data, multilevel logistic regression models were fitted to identify community and individual level factors associated with childhood MCV1. Four models were fitted: the first model without any explanatory variable (empty model) to detect the existence of possible contextual effect (model I), the second model with individual-level variables (model II), the third model with community-level variables (Model III) and the fourth model (Model IV) with both the individual- and community-level variables. Model comparison was done using deviance information criteria (DIC) and Akaike's Information Criterion (AIC). Finally, the fourth model (model IV) with the smallest value of the information criterion was selected as the final best fit model.

For measures of association (fixed effect), adjusted odds ratio with $95 \%$ confidence intervals was used to declare statistical significance.

For measures of variation (random effects), Intra-class correlation coefficient (ICC), median odds ratio (MOR) and proportional change in variance (PCV) statistics were computed. ICC is a measure of within-cluster variation, the variation between individuals within the same cluster, and it was calculated using the formula: ICC $=\frac{V_{A}}{V_{A}+\frac{\pi^{2}}{3}}=\frac{V_{A}}{V_{A}+3.29}$, where $\mathrm{V}_{\mathrm{A}}$ is the estimated variance in each model, which has been described elsewhere [27].

The total variation attributed to individual or/and community level factors at each model was measured by the proportional change in variance $(\mathrm{PCV})$, which was calculated as $P C V=\frac{V_{A}-V_{B}}{V_{A}}$, where $V_{A}=$ variance of the initial model, and $V_{B}=$ variance of the model with more terms [27].

The MOR is the median odds ratio between the individual of higher propensity and the individual of lower propensity when comparing two individuals from two different randomly chosen clusters and it measures the unexplained cluster heterogeneity, the variation between clusters by comparing two persons from two randomly chosen different clusters. It was computed using the formula: $\mathrm{MOR}=\exp \left(\sqrt{2 \times V_{\mathrm{A}}} \times 0.6745\right) \approx \exp \left(0.95 \sqrt{\mathrm{V}_{\mathrm{A}}}\right)$

, where $\mathrm{V}_{\mathrm{A}}$ is the cluster level variance $[27,28]$. The MOR measure is always greater than or equal to 1 . If the MOR is 1 , there is no variation between clusters [29].

\section{Ethical considerations}

The data of the 2016 Ethiopia demographic and health survey was used for this study with a permission from the Measure DHS program after being registered and submiting a request with briefly stated objctives of the study. Ethical approval was obtained from the Institutional Review Board of the Institute of Public Health of the University of 
Gondar and the ICF International Institutional Review Board. The data has been used only for this registered research and it could not be passed on to other researchers. The shape files for Ethiopia's administrative boundaries were obtained from the openAFRICA website [https://africaopendata.org/dataset/ethiopia-shapefiles] [30]. The detaile of the ethical issues has been published in the 2016 EDHS final report, which can be accessed at: http://www. dhsprogram.com/publications [19].

\section{Results}

\section{Characteristics of study participants and childhood MCV1} prevalence

Nearly half of the children (51\%) were in the 12-23 months age group with the mean age of 23 months ( $\pm 7 \mathrm{SD}$ ). Nearly $70 \%$ of the children had received pentavalent first dose vaccine (DPT1-HepB1-Hib1) and 49\% of children had received third dose of pentavalent vaccine (DPT3-HepB3-Hib3). Over $63 \%$ of mothers of the children had no education, one-fourth of them were in the poorest wealth quintile, and $81 \%$ had no regular media exposure.

The overall prevalence of childhood MCV1 in Ethiopia was $54.3 \%$ (95\% CI $=52.7-55.9$ ). Relatively the highest MCV1 prevalence (94\%) was in Addis Ababa town, and lowest in Afar region (29\%). The distance to a health facility was a big problem in the three-fifth $(60 \%)$ of respondents (Table 2).

\section{Spatial pattern of childhood MCV1}

The global spatial autocorrelation analysis based on feature locations and attribute values revealed a clustering pattern of childhood MCV1 across the study areas (Global Moran's I $=0.134, p$-value $<0.0001$ ) (Fig. 1 ).

The SaTScan spatial analysis detected a total of seven statistically significant SaTScan clusters areas with low childhood MCV1 coverage, which means that the prevalence of MCV1 is lower inside the SaTScan circular window compared to outside the SaTScan window. The most likely primary SaTScan cluster of areas with low coverage of MCV1 was detected in Afar region (LLR = 33.79, $p<0.01$ ), specifically in Zone 1 , Zone 2 and Zone 4 administrative zones and the most likely secondary Spatial SaTScan cluster (LLR $=26.76, p<0.01$ ) in Eastern Ethiopia, specifically in Afder, Shabelle, Korah, Doolo, Nogob, Jarar, Fatan administrative zones of Somali region.

The 3rd and 4th most likely clusters of areas with low rates of MCV1 were detected in Nuer and Agnuak Administrative zones of Gambella region ( $\mathrm{LLR}=17.73, P<0.01$ ) and Zone 2 administration of Afar region (LLR $=14.54, P<$ $0.01)$, respectively. In addition, the 5th most likely SaTScan cluster $(\mathrm{LLR}=14.49, P<0.01$ ) was detected in Illuababur and Jimma Administrative zones of Oromia Region, while the 6th most likely SaTScan cluster $(\mathrm{LLR}=14.18, P<0.01)$ in Zone 3 and Zone 4 of Afar region, North Shewa of Amhara region, West and East Hararge of Oromia Region and Siti zone of Somali region. The 7th most likely SaTScan cluster $(\mathrm{LLR}=12.27, P<0.01)$ was detected in East Hararge Zone of Oromia region, Harari Region and Fagan Zone of Somali region (Table 3 and Fig. 2).

\section{Factors associated with the childhood MCV1}

In the multilevel analysis, both individual and community level variables were included (Table 4), and the final best fit model (model IV) revealed that child's age; first and third dose pentavalent vaccination status; maternal age, maternal education; low household wealth index; region; and distance from health facility were factors significantly associated with childhood first dose measles vaccination.

Individual level factors: Children aged $24-35$ months old were 1.53 times $(\mathrm{AOR}=1.53 ; 95 \%$ CI: $1.25-1.88)$ more likely to be vaccinated for MCV1 than children aged 12-23 months old. Children who have received first dose pentavalent vaccine (DPT1-HepB1-Hib1) $($ AOR $=$ 9.09; 95\% CI: 6.86-12.03) and third dose pentavalent vaccine (DPT3-HepB3-Hib3) $\quad(\mathrm{AOR}=7.12 ; \quad 95 \% \quad \mathrm{CI}$ : 5.51-9.18) were more likely to receive first dose of measles vaccine. Children whose mothers' age 20-34 years were $55 \%(\mathrm{AOR}=0.45 ; 95 \% \mathrm{CI}$ : $0.27-0.76)$ less likely to receive MCV1 compared to those children whose mothers age $15-19$ years. In addition, children with maternal age $35-45$ years were $55 \%(\mathrm{AOR}=0.45 ; 95 \% \mathrm{CI}$ : 0.25-0.82) less likely to receive MCV1 compared to those children whose mothers age 15-19 years. Children with secondary and higher maternal education were more likely to receive $\mathrm{MVC} 1$ vaccination $(\mathrm{AOR}=1.62$; 95\% CI: 1.03-2.55) compared to children whose mothers had no education (Table 4).

Community level factors: Children in Afar ( $\mathrm{AOR}=0.32$; 95\% CI: 0.13-0.81), Oromia (AOR 0.24; 95\% CI 0.100.58), Somali (AOR $=0.39$; 95\% CI: 0.16-0.95), Gambella $(\mathrm{AOR}=0.39$; 95\%CI: 0.16-0.99) and Harari $(\mathrm{AOR}=0.27$; 95\%CI: 0.11-0.66) regions were less likely to receive MCV1 vaccination compared to children in Addis Ababa. The odds of MVC1 vaccination were increased by $31 \%$ $(\mathrm{AOR}=1.31 ; 95 \% \mathrm{CI}: 1.12-1.61)$ in children living in areas where distance to health facility is not a big problem compared to children living in areas where distance to health facility is a big problem (Table 4).

\section{Measures of variation (random-effects) and model fit statistics}

As the results of multilevel logistic regression analysis depicted in Table 5, the null model (Model I) revealed statistically significant variation in childhood MCV1 vaccination across communities $[\mathbf{\tau}=\mathbf{2 . 6 8}, \mathbf{p}<\mathbf{0 . 0 0 1}]$, in which $45 \%$ 
Table 2 Percentage of children age 12-35 months who received MCV1 at any time before the survey (weighted) by background characteristics, Ethiopia, 2016

\begin{tabular}{|c|c|c|c|c|}
\hline \multirow[t]{2}{*}{ Background Characteristics } & \multicolumn{2}{|c|}{ Total number of Children } & \multicolumn{2}{|c|}{ Children who received MCV1 } \\
\hline & $\bar{N}$ & $\%$ & $\overline{\mathrm{N}}$ & $\%$ \\
\hline \multicolumn{5}{|l|}{ Individual level characteristics } \\
\hline \multicolumn{5}{|c|}{ Child Age (in Months) (Mean $=22.95(S D \pm 7.04)$} \\
\hline $12-23$ & 1976 & 51.0 & 1069 & 54.1 \\
\hline $24-35$ & 1901 & 49.0 & 1036 & 54.5 \\
\hline \multicolumn{5}{|l|}{ Sex of child } \\
\hline Male & 1935 & 49.9 & 1056 & 54.6 \\
\hline Female & 1941 & 50.1 & 1049 & 54 \\
\hline \multicolumn{5}{|l|}{ Birth Order } \\
\hline 1 & 753 & 19.4 & 451 & 59.9 \\
\hline $2-3$ & 1161 & 29.9 & 674 & 58.1 \\
\hline $4-5$ & 900 & 23.2 & 475 & 52.8 \\
\hline $6+$ & 1063 & 27.4 & 505 & 47.5 \\
\hline \multicolumn{5}{|l|}{ Wanted child } \\
\hline Wanted then & 2832 & 73.1 & 1491 & 52.7 \\
\hline Wanted later & 702 & 18.1 & 430 & 61.3 \\
\hline Wanted no more & 343 & 8.8 & 183 & 53.5 \\
\hline \multicolumn{5}{|l|}{ DPT1-HepB1-Hib1 vaccine } \\
\hline Not vaccinated & 1158 & 29.9 & 121 & 10.4 \\
\hline Vaccinated & 2718 & 70.1 & 1984 & 73 \\
\hline \multicolumn{5}{|l|}{ DPT3-HepB3-Hib3 vaccine } \\
\hline Not vaccinated & 1983 & 51.2 & 505 & 25.5 \\
\hline Vaccinated & 1893 & 48.8 & 1599 & 84.5 \\
\hline \multicolumn{5}{|l|}{ Maternal age (years) } \\
\hline $15-19$ & 137 & 3.5 & 77 & 56.2 \\
\hline $20-34$ & 2850 & 73.5 & 1587 & 55.7 \\
\hline $35-49$ & 889 & 22.9 & 441 & 49.6 \\
\hline \multicolumn{5}{|l|}{ Religion } \\
\hline Orthodox & 1349 & 34.8 & 887 & 65.8 \\
\hline Muslim & 1530 & 39.5 & 617 & 40.4 \\
\hline Protestant & 861 & 22.2 & 529 & 61.4 \\
\hline Others $^{\mathrm{a}}$ & 136 & 3.5 & 71 & 52.2 \\
\hline \multicolumn{5}{|l|}{ Mother's educational } \\
\hline No education & 2474 & 63.8 & 1188 & 48 \\
\hline Primary & 1100 & 28.4 & 669 & 60.8 \\
\hline Secondary \& Higher & 302 & 7.8 & 248 & 82.1 \\
\hline \multicolumn{5}{|c|}{ Husband/partner's education $(N=3655)$} \\
\hline No education & 1746 & 47.8 & 820 & 47 \\
\hline Primary & 1462 & 40.0 & 838 & 57.3 \\
\hline Secondary \& Higher & 447 & 12.2 & 319 & 71.4 \\
\hline \multicolumn{5}{|l|}{ Mother's occupation } \\
\hline Did not work & 2071 & 53.4 & 1024 & 49.4 \\
\hline Non-Professional & 1731 & 44.7 & 1025 & 59.2 \\
\hline
\end{tabular}


Table 2 Percentage of children age 12-35 months who received MCV1 at any time before the survey (weighted) by background characteristics, Ethiopia, 2016 (Continued)

\begin{tabular}{|c|c|c|c|c|}
\hline \multirow[t]{2}{*}{ Background Characteristics } & \multicolumn{2}{|c|}{ Total number of Children } & \multicolumn{2}{|c|}{ Children who received MCV1 } \\
\hline & $\mathrm{N}$ & $\%$ & $\mathrm{~N}$ & $\%$ \\
\hline Professional & 74 & 1.9 & 56 & 75.7 \\
\hline \multicolumn{5}{|l|}{ Father's occupation ( $N=3655)$} \\
\hline Did not work & 275 & 7.5 & 111 & 40.2 \\
\hline Nonprofessional & 620 & 17.0 & 303 & 48.9 \\
\hline Professional & 2760 & 75.5 & 1564 & 56.7 \\
\hline \multicolumn{5}{|c|}{ Maternal relation to the household dead } \\
\hline Wife & 3091 & 79.7 & 1670 & 54 \\
\hline Head & 406 & 10.5 & 224 & 55.2 \\
\hline Daughter & 211 & 5.4 & 122 & 57.8 \\
\hline Others $^{b}$ & 169 & 4.4 & 89 & 52.7 \\
\hline \multicolumn{5}{|l|}{ Sex of the household head } \\
\hline Male & 3314 & 85.5 & 1792 & 54.1 \\
\hline Female & 562 & 14.5 & 312 & 55.5 \\
\hline Number of living children & & & & 0 \\
\hline 1 & 684 & 17.6 & 413 & 60.4 \\
\hline $2-3$ & 1281 & 33.0 & 759 & 59.3 \\
\hline $4-5$ & 1022 & 26.4 & 529 & 51.8 \\
\hline $6+$ & 890 & 23.0 & 404 & 45.4 \\
\hline \multicolumn{5}{|c|}{ Maternal health care decision making $(N=3655)$} \\
\hline Jointly with her husband & 2439 & 66.7 & 1333 & 54.7 \\
\hline Husband/partner alone & 727 & 19.9 & 351 & 48.3 \\
\hline By herself alone & 479 & 13.1 & 286 & 59.6 \\
\hline Others & 10 & 0.3 & 8 & 80 \\
\hline \multicolumn{5}{|l|}{ Wealth index } \\
\hline Poorest & 965 & 24.9 & 412 & 42.7 \\
\hline Poorer & 860 & 22.2 & 445 & 51.7 \\
\hline Middle & 808 & 20.8 & 419 & 51.9 \\
\hline Richer & 676 & 17.4 & 393 & 58.1 \\
\hline Richest & 567 & 14.6 & 436 & 76.9 \\
\hline \multicolumn{5}{|l|}{ Mass Media Exposure } \\
\hline Not regular & 3154 & 81.4 & 1601 & 50.8 \\
\hline Regular & 722 & 18.6 & 504 & 69.7 \\
\hline \multicolumn{5}{|l|}{ Community level characteristics } \\
\hline \multicolumn{5}{|l|}{ Region } \\
\hline Addis Ababa & 95 & 2.5 & 90 & 93.8 \\
\hline Tigray & 279 & 7.2 & 227 & 81.1 \\
\hline Afar & 42 & 1.1 & 12 & 28.6 \\
\hline Amhara & 718 & 18.5 & 434 & 60.4 \\
\hline Oromia & 1712 & 44.2 & 722 & 42.1 \\
\hline Somali & 132 & 3.4 & 47 & 35.6 \\
\hline Benishangul Gumuz & 43 & 1.1 & 32 & 76.2 \\
\hline SNNPR & 818 & 21.1 & 517 & 63.1 \\
\hline
\end{tabular}


Table 2 Percentage of children age 12-35 months who received MCV1 at any time before the survey (weighted) by background characteristics, Ethiopia, 2016 (Continued)

\begin{tabular}{|c|c|c|c|c|}
\hline \multirow[t]{2}{*}{ Background Characteristics } & \multicolumn{2}{|c|}{ Total number of Children } & \multicolumn{2}{|c|}{ Children who received MCV1 } \\
\hline & $\mathrm{N}$ & $\%$ & $\mathrm{~N}$ & $\%$ \\
\hline Gambella & 10 & 0.2 & 6 & 60 \\
\hline Harari & 10 & 0.2 & 5 & 50 \\
\hline Dire Dawa & 17 & 0.4 & 14 & 82.4 \\
\hline \multicolumn{5}{|l|}{ Residence } \\
\hline Urban & 433 & 11.2 & 337 & 77.8 \\
\hline Rural & 3443 & 88.8 & 1768 & 51.4 \\
\hline \multicolumn{5}{|l|}{ Distance to health facility } \\
\hline Big Problem & 2332 & 60.2 & 1114 & 47.8 \\
\hline Not a big problem & 1545 & 39.8 & 991 & 64.1 \\
\hline Total & 3876 & 100 & 2105 & 54.3 \\
\hline
\end{tabular}

${ }^{\mathrm{a}}$ Catholic, traditional and other unclassified

${ }^{\mathrm{b}}$ Daughter-in-low, sister, other relative, no relation

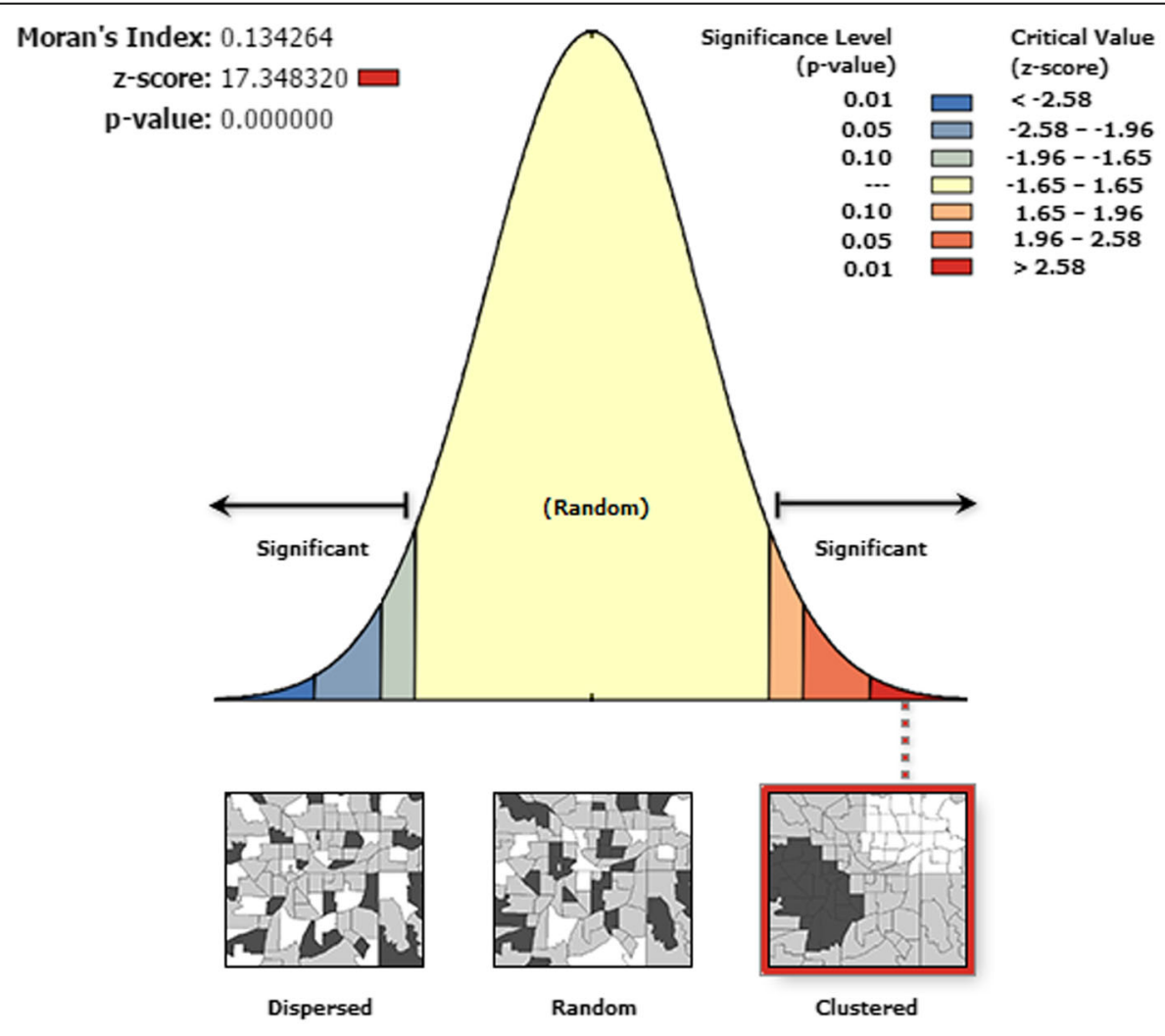

Given the $z$-score of 17.3483204118 , there is a less than $1 \%$ likelihood that this clustered pattern could be the result of random chance.

Fig. 1 The global spatial autocorrelation based on feature locations and attribute values (MCV1) across the study areas in Ethiopia, 2016 
Table 3 The most likely clusters from a purely spatial scan statistic (discrete Poisson model) of children received MCV1 in Ethiopia, 2016

\begin{tabular}{|c|c|c|c|c|c|c|}
\hline Clusters & Regional location (Zones) & $\begin{array}{l}\text { Number of } \\
\text { clusters }\end{array}$ & $\begin{array}{l}\text { Radius } \\
(\mathrm{km})\end{array}$ & $\operatorname{LLR}^{\mathrm{a}}$ & $C . V^{b}$ & $\begin{array}{l}\text { P- } \\
\text { Value }\end{array}$ \\
\hline $\begin{array}{l}\text { Primary } \\
\text { cluster }\end{array}$ & Afar Region (Zone 1, Zone 2 \& Zone 3) & 30 & 265.1 & 33.79 & 9.85 & 0.001 \\
\hline $\begin{array}{l}\text { Secondary } \\
\text { cluster }\end{array}$ & Somali Region (Afder, Shabelle, Korah, Doolo, Nogob, Jarar, Fatan) & 42 & 339.6 & 26.76 & 9.83 & 0.001 \\
\hline 3rd cluster & Gambella Region (Nuer \& Agnuak) & 15 & 91.7 & 17.73 & 9.45 & 0.001 \\
\hline 4th cluster & Afar Region (Zone 2) & 2 & 8.9 & 14.54 & 9.28 & 0.001 \\
\hline 5th cluster & Oromia Region (Illuababur \& Jimma) & 8 & 78.7 & 14.49 & 9.45 & 0.002 \\
\hline 6th cluster & $\begin{array}{l}\text { Afar Region (Zone } 3 \text { and 4), Amhara Region (North Shewa), Oromia Region (West and } \\
\text { East Hararge) and Somali Region (Siti) }\end{array}$ & 28 & 139.1 & 14.18 & 9.40 & 0.001 \\
\hline 7th cluster & Oromia Region (East Hararge Zone), Harari and Somali Region (Fatan Zone) & 26 & 39.8 & 12.27 & 9.69 & 0.005 \\
\hline
\end{tabular}

${ }^{\text {aLog likelihood ratio }}$

${ }^{\mathrm{b}}$ Standard Monte Carlo Critical Value for 0.05 significance level

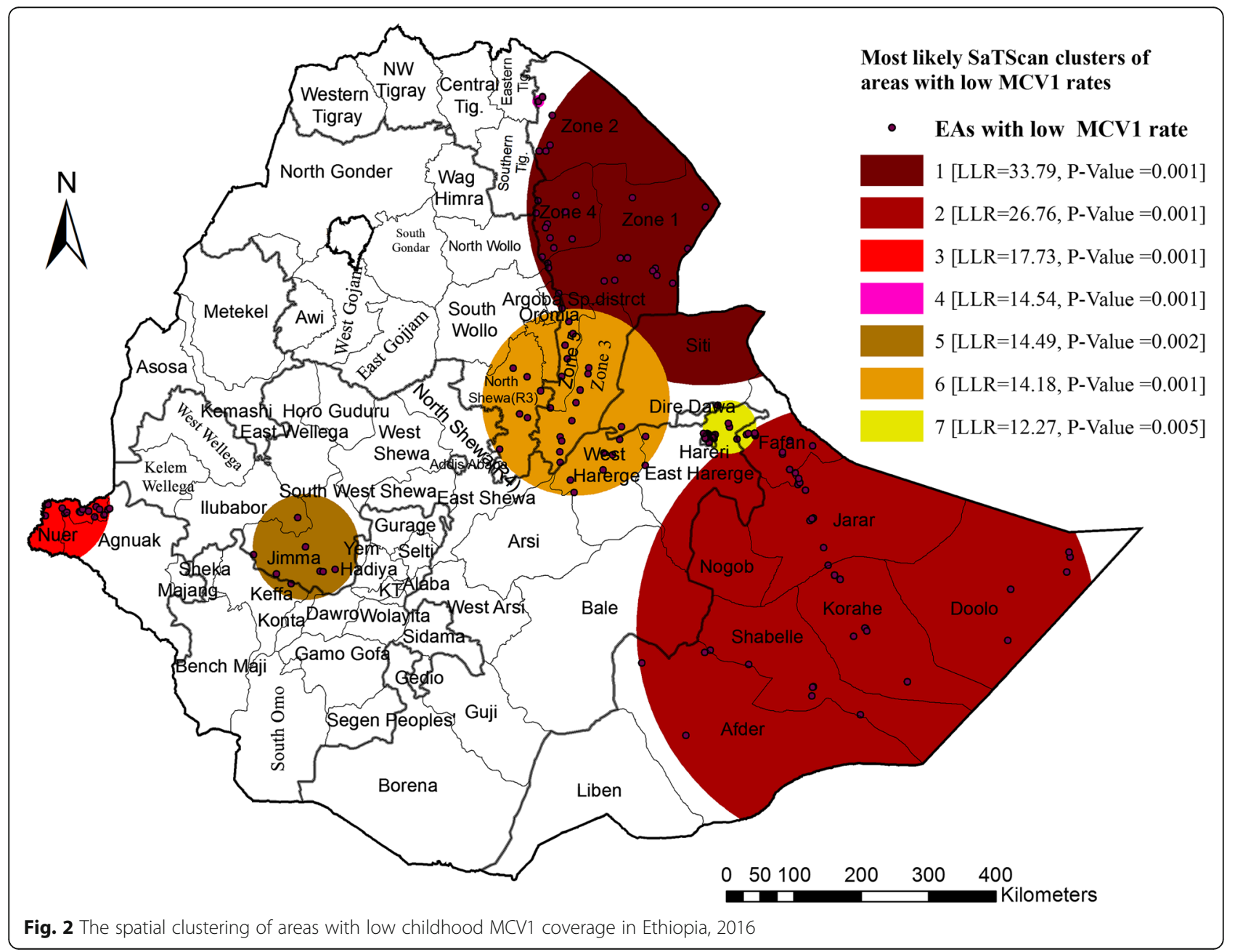


Table 4 Multilevel logistic regression analysis of individual and community level factors associated with childhood MCV1 in Ethiopia, 2016

\begin{tabular}{|c|c|c|c|}
\hline Variables & $\begin{array}{l}\text { Model II } \\
\text { AOR }(95 \% \mathrm{Cl})\end{array}$ & $\begin{array}{l}\text { Model III } \\
\text { AOR }(95 \% \text { Cl) }\end{array}$ & $\begin{array}{l}\text { Model IV } \\
\text { AOR }(95 \% \mathrm{Cl})\end{array}$ \\
\hline \multicolumn{4}{|l|}{ Individual level factors } \\
\hline \multicolumn{4}{|l|}{ Child characteristics } \\
\hline \multicolumn{4}{|l|}{ Child's age (months) } \\
\hline $12-23$ & 1.00 & - & 1.00 \\
\hline $24-35$ & $1.53(1.2-1.88)$ & - & $1.53(1.25-1.88)$ \\
\hline \multicolumn{4}{|l|}{ Sex of child } \\
\hline Male & 1.00 & - & 1.00 \\
\hline Female & $1.11(0.92-1.35)$ & - & $1.10(0.91-1.34)$ \\
\hline \multicolumn{4}{|l|}{ Birth Order } \\
\hline 1 & 1.00 & - & 1.00 \\
\hline $2-3$ & $1.01(0.62-1.63)$ & - & $1.00(0.61-1.63)$ \\
\hline $4-5$ & $1.03(0.55-1.93)$ & - & $1.03(0.55-1.92)$ \\
\hline $6+$ & $0.86(0.41-1.81)$ & - & $0.87(0.42-1.83)$ \\
\hline \multicolumn{4}{|l|}{ Child Wanted } \\
\hline Wanted then & 1.00 & - & 1.00 \\
\hline Wanted later & $0.93(0.70-1.23)$ & - & $0.94(0.71-1.25)$ \\
\hline Wanted no more & $1.52(0.98-2.37)$ & - & $1.58(1.00-2.47)$ \\
\hline \multicolumn{4}{|c|}{ DPT1-HepB1-Hib1 (Pentavalent first dose) vaccine } \\
\hline Not vaccinated & 1.00 & - & 1.00 \\
\hline Vaccinated & $9.23(6.98-12.22)$ & - & $9.09(6.86-12.03)$ \\
\hline \multicolumn{4}{|c|}{ DPT3-HepB3-Hib3 (Pentavalent third dose) vaccine } \\
\hline Not vaccinated & 1.00 & - & 1.00 \\
\hline Vaccinated & $8.15(6.33-10.48)$ & - & $7.12(5.51-9.18)$ \\
\hline \multicolumn{4}{|l|}{ Maternal Characteristics } \\
\hline \multicolumn{4}{|l|}{ Maternal age (in years) } \\
\hline $15-19$ & 1.00 & - & 1.00 \\
\hline $20-34$ & $0.46(0.28-0.78)$ & - & $0.45(0.27-0.76)$ \\
\hline $35-49$ & $0.49(0.27-0.90)$ & - & $0.45(0.25-0.82)$ \\
\hline \multicolumn{4}{|l|}{ Religion } \\
\hline Orthodox Christian & 1.00 & - & 1.00 \\
\hline Muslim & $0.71(0.54-0.94)$ & - & $0.95(0.65-1.38)$ \\
\hline Protestant & $1.04(0.74-1.46)$ & - & $1.32(0.85-2.03)$ \\
\hline Others $^{a}$ & $1.05(0.54-2.03)$ & - & $1.32(0.66-2.62)$ \\
\hline \multicolumn{4}{|l|}{ Maternal Education } \\
\hline No education & 1.00 & - & 1.00 \\
\hline Primary & $1.00(0.78-1.29)$ & - & $0.99(0.77-1.28)$ \\
\hline Secondary and higher & $1.71(1.10-2.66)$ & - & $1.62(1.03-2.55)$ \\
\hline \multicolumn{4}{|l|}{ Mother's occupation } \\
\hline Did not work & 1.00 & - & 1.00 \\
\hline Non-professional & $1.07(0.86-1.33)$ & - & $1.04(0.83-1.29)$ \\
\hline Professional & $0.97(0.40-2.35)$ & - & $0.93(0.38-2.25)$ \\
\hline \multicolumn{4}{|c|}{ Mather's relation to the household head } \\
\hline Wife & 1.00 & - & 1.00 \\
\hline
\end{tabular}


Table 4 Multilevel logistic regression analysis of individual and community level factors associated with childhood MCV1 in Ethiopia, 2016 (Continued)

\begin{tabular}{|c|c|c|c|}
\hline Variables & $\begin{array}{l}\text { Model II } \\
\text { AOR (95\% Cl) }\end{array}$ & $\begin{array}{l}\text { Model III } \\
\text { AOR (95\% Cl) }\end{array}$ & $\begin{array}{l}\text { Model IV } \\
\text { AOR }(95 \% \text { CI) }\end{array}$ \\
\hline Head & $0.72(0.37-1.42)$ & - & $0.70(0.35-1.38)$ \\
\hline Daughter & $1.39(0.83-2.32)$ & - & $1.35(0.81-2.26)$ \\
\hline Others $^{\mathrm{b}}$ & $1.08(0.61-1.91)$ & - & $1.05(0.58-1.87)$ \\
\hline \multicolumn{4}{|l|}{ Sex of the household head } \\
\hline Male & 1.00 & - & 1.00 \\
\hline Female & $1.54(0.83-2.87)$ & - & $1.57(0.84-2.93)$ \\
\hline Number of living children & 1.00 & & \\
\hline 1 & 1.00 & - & 1.00 \\
\hline $2-3$ & $1.21(0.74-1.97)$ & - & $1.21(0.74-1.98)$ \\
\hline $4-5$ & $1.26(0.66-2.40)$ & - & $1.29(0.68-2.47)$ \\
\hline $6+$ & $1.16(0.55-2.48)$ & - & $1.18(0.55-2.53)$ \\
\hline \multicolumn{4}{|l|}{ Wealth index } \\
\hline Poorest & 1.00 & - & 1.00 \\
\hline Poorer & $1.12(0.83-1.52)$ & - & $1.16(0.85-1.59)$ \\
\hline Middle & $0.94(0.68-1.30)$ & - & $0.99(0.71-1.40)$ \\
\hline Richer & $1.06(0.75-1.50)$ & - & $1.18(0.83-1.70)$ \\
\hline Richest & $1.35(0.93-1.98)$ & - & $1.34(0.82-2.20)$ \\
\hline \multicolumn{4}{|c|}{ Regular exposure to mass media } \\
\hline No & 1.00 & - & 1.00 \\
\hline Yes & $1.33(0.98-1.80)$ & - & $1.32(0.97-1.79)$ \\
\hline \multicolumn{4}{|l|}{ Community level factors } \\
\hline \multicolumn{4}{|l|}{ Region } \\
\hline Addis Ababa & - & 1.00 & 1.00 \\
\hline Tigray & - & $0.72(0.30-1.73)$ & $0.65(0.27-1.56)$ \\
\hline Afar & - & $0.04(0.02-0.09)$ & $0.32(0.13-0.81)$ \\
\hline Amhara & - & $0.25(0.10-0.58)$ & $0.46(0.19-1.11)$ \\
\hline Oromia & - & $0.12(0.05-0.27)$ & $0.24(0.10-0.58)$ \\
\hline Somali & - & $0.05(0.02-0.13)$ & $0.39(0.16-0.95)$ \\
\hline Benishangul & - & $0.60(0.25-1.47)$ & $0.63(0.25-1.56)$ \\
\hline SNNPR & - & $0.32(0.14-0.75)$ & $0.42(0.17-1.01)$ \\
\hline Gambella & - & $0.15(0.06-0.36)$ & $0.39(0.16-0.99)$ \\
\hline Harari & - & $0.11(0.04-0.25)$ & $0.27(0.11-0.66)$ \\
\hline Dire Dawa & - & $0.63(0.25-1.60)$ & $0.69(0.27-1.79)$ \\
\hline \multicolumn{4}{|l|}{ Residence } \\
\hline Urban & - & 1.00 & 1.00 \\
\hline Rural & - & $0.30(0.21-0.44)$ & $1.03(0.64-1.65)$ \\
\hline \multicolumn{4}{|l|}{ Distance to Health facility } \\
\hline Big problem & - & 1.00 & 1.00 \\
\hline Not a big problem & - & $1.42(1.17-1.72)$ & $1.31(1.12-1.61)$ \\
\hline
\end{tabular}

${ }^{a}$ Catholic, traditional and other unclassified 
Table 5 Measures of variation (random intercept models) and model fit statistics in childhood MCV1 in Ethiopia, 2016

\begin{tabular}{|c|c|c|c|c|}
\hline Measures of variation & Model $1^{a}$ & Model $2^{b}$ & Model $3^{c}$ & Model $4^{d}$ \\
\hline \multicolumn{5}{|l|}{ Community level } \\
\hline Variance (SE) & $2.676(0.091)^{*}$ & $0.556(0.085)^{*}$ & $1.117(0.074)^{*}$ & $0.479(0.086)^{*}$ \\
\hline PCV (\%) & Reference & 79.2 & 58.3 & 82.1 \\
\hline ICC (\%) & 44.9 & 14.5 & 25.3 & 12.7 \\
\hline $\mathrm{MOR}^{\mathrm{e}}$ & 4.73 & 2.03 & 2.73 & 1.93 \\
\hline \multicolumn{5}{|l|}{ Model fit statistics } \\
\hline DIC (-2log likelihood) & 4462 & 2984 & 4142 & 2953 \\
\hline AIC & 4466 & 3050 & 4170 & 3043 \\
\hline
\end{tabular}

SE Standard Error; PCV Proportional Change in Variance, ICC Intraclass Correlation Coefficient, MOR Median Odds Ratio, DIC Deviance Information Criterion, AIC Akaike's Information Criterion

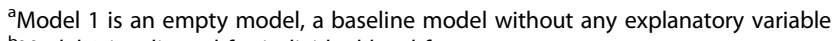

${ }^{\mathrm{b}}$ Model 2 is adjusted for individual-level factors

${ }^{\mathrm{c}}$ Model 3 is adjusted for community-level factors

${ }^{\mathrm{d}}$ Model 4 is final model adjusted for both individual and community-level factors

eIncreased risk (in median) that one would have if moving to a neighborhood/cluster with a higher risk

${ }^{*} P$-value $<0.001$

variation in the odds of a child being MCV1 vaccinated is attributed to community-level factors (ICC $=45 \%$ ).

After adjusting the model for individual level factors (Model 2), the variation in the odds of a child receiving MCV1 remained statistically significant $[\boldsymbol{\tau}=\mathbf{0 . 5 6}, \boldsymbol{p}<\mathbf{0 . 0 0 1}]$ across the communities, with $79 \%$ of variation in the odds of children who received MCV1 was attributed to the individual factors and $15 \%$ of the variance in MCV1 among the children was attributed to community-level factors.

Model 3, which is adjusted for community-level factors, revealed an increased variance of a child being vaccinated for MCV1 $[\boldsymbol{\tau}=\mathbf{1 . 1 2}, \boldsymbol{p}<\mathbf{0 . 0 0 1}]$ across the communities, as compared to the variance reported in model 2. In this model, the community level factors explained the $58 \%$ of the variability in the odds of children receiving MCV1 $(\mathrm{PCV}=58.3 \%)$, and $25.3 \%$ of the variation among the clusters was attributed to community level factors (ICC $=25.3 \%$ ).

The final best-fit model (model IV), which adjusted for both individual and community-level factors simultaneously, depicted statistically significant variability to the odds of a child being MCV1 vaccinated $[\boldsymbol{\tau}=\mathbf{0 . 4 8 , \boldsymbol { p } <}$ 0.001]. In this final best fit model, about $13 \%$ of the variability among communities in the odds of a child being MCV1 vaccinated was due to the community-level factors (ICC $=12.7 \%$ ) and about $82 \%$ of the variance in the odds of MCV1 vaccination (PCV $=82.1 \%$ ) across communities was attributed to both individual and community-level factors.

In this study, the MOR shows the extent to which the child probability of receiving MCV1 is determined by residential area and is therefore appropriate for quantifying contextual phenomena. It quantifies the variation in MCV1 between clusters (the second-level variation) by comparing two children from two randomly chosen, different clusters. MOR greater than 1 in all models suggests a considerable between-cluster variation in childhood MCV1. Including both individual, and community level factors reduced the unexplained heterogeneity in MCV1 between communities from MOR of 4.73 in the null model to the MOR of 1.93 in the final model.

\section{Discussion}

In this study, a total of 3722 children aged 12-35 months nested within 611 clusters were included from the 2016 EDHS data. The prevalence of childhood MCV1 was found to be $54.3 \%$ (95\% CI $=52.7-55.9)$ which was low compared to the recent DHS reports of most low and middle income countries such as Egypt, 96\% [31], Kenya, 87\% [32], Rwanda, 95\% [33], Ghana, 89\% [34], Zimbabwe, 82\% [35] and Uganda, 80\% [36]. It was also low as compared to a local survey finding in the selected zones of Ethiopia by JSI-110k, 80\% [37], the national report in $2015,87 \%$ [38]. In addition the prevalence of MCV1 is lower than the 2016 national target for childhood MCV1, 91\% [38] and the recommended herd immunity threshold, 95\% [8,39]. This childhood MCV1 coverage below the recommended herd immunity threshold (95\%) may indicate that not only the country but also the regions with high levels of childhood MCV1 coverage may still be at considerable risk for measles outbreaks.

Exploring spatial heterogeneity in childhood vaccination is gaining attention at all spatial scales to identify gaps and intervene accordingly [40]. In the global spatial autocorrelation analysis of this study, a clustering pattern of childhood MCV1 across the study areas was observed (Global Moran's $\mathrm{I}=0.134, p$-value $<0.0001$ ). This indicates that approximately the same coverages of childhood MCV1 were aggregated in specific areas. Hence, the SaTScan spatial analysis detected seven statistically significant most likely SaTScan clusters of areas with low MCV1 
coverage. The most likely primary SaTScan cluster of areas with low MCV1 coverage was detected in Afar region; specifically in Zone 1, Zone 2 and Zone 4 administrative zones (LLR $=33.79, p<0.01$ ), and the most likely secondary SaTScan cluster in Somali region, specifically in Afder, Shabelle, Korah, Doolo, Nogob, Jarar and Fatan administrative zones (LLR $=26.76, p<0.01$ ). The 3 rd and 4th most likely clusters of areas with low MCV1 coverage were detected in Gambella region; specifically in Nuer and Agnuak Administrative zones (LLR $=17.73, P<0.01$ ) and Afar region, particularly in Zone 2 administrative zone $(\mathrm{LLR}=14.54, P<0.01)$, respectively. In addition, the 5th most likely SaTScan cluster $(\mathrm{LLR}=14.49, P<0.01)$ was detected in Illuababur \& Jimma Administrative zones of Oromia Region, while the 6th most likely SaTScan cluster (LLR $=14.18, P<0.01)$ in zone 3 and zone 4 administrative zones of Afar region, North Shewa zone of Amhara region, West and East Hararge zones of Oromia region and Siti zone of Somali region. The last (7th) most likely SaTScan cluster $(\mathrm{LLR}=12.27, P<0.01)$ was detected in East Hararge zone of Oromia region, Fatan zone of Somali region, and Harari region. This local clustering of low childhood MCV1 coverages indicates that children who lived in the above mentioned geographical locations had a low probability of receiving MCV1 compared with those who lived outside the SaTScan clusters. It may be due to differences in health service accessibility and utilization, as well as socio-cultural differences in the community. This geographical clustering low MCV1 coverage may suggest that regions with high coverage of childhood MCV1 may be at risk for measles outbreaks [41].

As the multilevel analysis showed, the variation in the childhood MCV1 vaccination was attributed to both individual and community level factors. In the final model (model IV), individual and community-level factors accounted for about $82.1 \%$ of the variation observed for childhood MCV1. It is supported by other findings in Ethiopia [42] and Democratic Republic of Congo [43].

Children aged 24-35 months were more likely to receive MCV1 compared to children aged 12-23 months (AOR = 1.53; 95\% CI: $1.25-1.88)$. This could be due to late initiation of childhood vaccination and Vaccine hesitancy for early ages. This indicates delaying in childhood vaccination which extends the period of vulnerability of children to vaccine preventable diseases [44]. We also found that children who have received the first dose of pentavalent vaccine $(\mathrm{AOR}=$ 9.09; 95\% CI: 6.86-12.03) and third dose of pentavalent vaccine (AOR $=7.12$; 95\% CI: 5.51-9.18) were more likely to receive MCV1. This may be due to differences in childhood vaccination service availability and utilization among communities. It could also be justified as; women whose children lacked the first and third doses of pentavalent vaccination may miss the opportunities for information on the importance of childhood measles vaccination. Pentavalent first dose vaccination coverage is a good proxy indicator for the availability of access to and initial use of childhood vaccination services [13]. Hence, a high proportion of pentavalent first dose coverage may indicate the availability of childhood vaccination services in the communities. In addition, the third dose pentavalent vaccination coverage indicates the continuity of use by parents or care takers, client satisfaction with services, and capability of the system to deliver a series of vaccinations [13]. Hence, a high proportion of pentavalent third dose vaccination may indicate better childhood vaccination service utilization and the health system performance in relation to vaccination services.

Maternal education was identified as a strong predictor of childhood immunization in other several studies [45-48]. Children from mothers with secondary or higher education had higher odds of being vaccinated for MCV1 (AOR $=1.62 ; 95 \%$ CI: 1.03-2.55). This finding is supported by other studies in Ethiopia [42], Democratic Republic of Congo [43], Nigeria [49, 50], Kenya [51] and in India [52] and it is not surprising that educated mothers are generally more likely to utilize health care services including childhood immunization services, and have better communication skills $[53,54]$.

From the community level characteristics, geographical region was a significant predictor of childhood MCV1. Children who were living in Afar, Oromia, Somali, Gambella and Harari regions were less likely to receive MCV1 as compared to children lived in Addis Ababa. This could be justified by the regional differences in some background characteristics such as culture, religion, economical status, vaccine supply, and availability and accessibility of immunization health services.

In contrast to the findings that have been documented elsewhere [55-58], maternal place of residence was not a significant predictor of childhood MCV1. This may be due to differences in study period, and sample size. However, the finding is consistent with the findings of other studies conducted in central Ethiopia and Nigeria, in which a non-significant association between place of residence and likelihood of childhood MCV1 [45, 59]. This may suggest a need for further investigation.

Finally, this study revealed that children who lived in areas where distance from health facility is not a big problem were more likely to receive childhood MCV1 that is consistent with a study finding in sub-Saharan Africa [60].

EDHS is a national and subnational representative household survey with a high response rate and the findings are generalizable to the national and subnational populations. Hence, generalizability is the strength of this study. Applying spatial scan statistics and employing multilevel regression models to identify both individual and community level factors that could not be addressed with ordinary logistic regression model are other important strengths. However, recall bias may be introduced 
due to the retrospective nature of the data, and the maternal verbal reports for childhood vaccination.

\section{Conclusion}

A clustered pattern of areas with low childhood MCV1 coverage was observed in Ethiopia. Statistically significant local clusters of areas with low childhood MCV1 were detected in Somali, Afar, Gambella, and Oromia regions of the country. Both the individual level characteristics (child's age, first and third doses of pentavalent vaccination, maternal age and education) and community level characteristics (geographic region and distance from health facility) were statistically significant predictors of childhood MCV1. Hence, it is good if the federal ministry of health and other concerned child health programmers give priority of the areas with low MCV1 coverage identified in this study. It is also better to consider the individual and community level determinant factors identified in this study.

\section{Abbreviations \\ AIC: Akaike's information criterion; AOR: Adjusted odds ratio; Cl: Confidence intervals; COR: Crude odd ratio; DIC: Deviance information criterion; DPT- HepB-Hib: A combination vaccine containing diphtheria, pertussis, tetanus toxoid, hepatitis B and Haemophilus influenza type b; EAs: Enumeration areas; EDHS: Ethiopian demographic and health survey; GIS: Geographic information system; ICC: Intra-cluster correlation; IR: Incidence rate; LLR: Log likelihood ratio; MCV1: First dose of measles-containing vaccine; MOR: Median odds ratio; PCV: Proportional change in variance; SD: Standard deviation; SNNPR: Southern Nations, Nationalities, and People Region; WHO: World health organization}

\section{Acknowledgements}

The authors would like to thank the MeasureDHS program for their permission to download and use the 2016 Ethiopia demographic and Health survey datasets.

\section{Authors' contributions}

$\Pi$ conceived the study, conducted the statistical analysis and interpretation, and drafted the manuscript. LD and AN assisted the data analysis and interpretation, reviewed the draft of consecutive manuscript and did the final editing. All of the authors read and approved the final version of the manuscript.

\section{Funding}

The authors have no support or funding to report.

\section{Availability of data and materials}

The datasets generated and/or analyzed during the current study are available in the MeasureDHS Program repository, (https://www.dhsprogram. com/data/dataset_admin) to all registered users.

\section{Ethics approval and consent to participate}

Ethical approval was obtained from the Institutional Review Board of the Institute of Public Health, the University of Gondar and the ICF International Institutional Review Board. The data has been used only for this registered research and it could not be passed on to other researchers.

\section{Consent for publication}

Not applicable.

\section{Competing interests}

The authors declare that they have no competing interests.

\section{Author details}

${ }^{1}$ Ethiopian Field Epidemiology and Laboratory Training Program, Department of Epidemiology and Biostatistics, Institute of Public Health, College of
Medicine and Health Sciences, University of Gondar, P.O. Box 169, Gondar, Ethiopia. ${ }^{2}$ Department of Reproductive Health and Population Studies, School of Public Health, College of Medicine and Health Sciences, Bahir Dar University, P.O. Box 79, Bahir Dar, Ethiopia. ${ }^{3}$ Department of Epidemiology and Biostatistics, Institute of Public Health, College of Medicine and Health Sciences, University of Gondar, P.O. Box 169, Gondar, Ethiopia. ${ }^{4}$ Department of Human Nutrition and Food Sciences, College of Health Sciences, Debre Markos University, P.O. Box 269, Debre Markos, Ethiopia. ${ }^{5}$ Academic Center of Excellence for Human Nutrition, Food Science and Post-harvest Technology, Hawassa University, Hawassa, Ethiopia.

Received: 16 January 2019 Accepted: 21 August 2019

Published online: 30 August 2019

\section{References}

1. Ethiopian Health and Nutrition Research Institute (EHNRI): Guideline on measles surveillance and outbreak management, ed. 3rd. 2012, Addis Ababa, Ethiopia. Available at: http://www.ephi.gov.et/index.php/2014-04-1 0-07-22-18/guidelines.

2. Perry RT, et al. Progress toward regional measles elimination - worldwide, 2000-2014. MMWR Morb Mortal Wkly Rep. 2015;64:1246-51.

3. World Health Organization (2016). Immunization Coverage: Fact sheet No. 286. Available at: www.who.int/mediacentre/factsheets/fs286/en/ (Accessed 24 Jan 2018).

4. WHO: Summary of the WHO position on Measles Vaccine. 2017. Available at: http://www.who.int/entity/immunization/policy/position_papers/WHO_ PP_measles_vaccine_summary_2017.pdf. (Accessed 26 Feb 2018).

5. World Health Organization (2012): Global measles and rubella strategic plan: 2012-2020.

6. Strategic Advisory Group of Experts on Immunization (SAGE): 2016. Midterm review report of global vaccine action plan.

7. $\mathrm{WHO}$ and UNICEF. Estimates for National Immunization Coverage (WUENIC), 2010-2015.

8. WHO. WER Index 2016: Weekly Epidemiological Record. 2016;91(45):525-36 Available at: http://www.who.int/wer/2016/wer9145/en/.

9. WHO, Department of evidence, information and research estimates for child causes of death, 2000-2015 (updated 5 February 2016).

10. Merlo J, et al. A brief conceptual tutorial of multilevel analysis in social epidemiology: linking the statistical concept of clustering to the idea of contextual phenomenon. J Epidemiol Community Health. 2005;59(6):443-9.

11. Akalu HB. Review on measles situation in Ethiopia; past and present. J Trop Dis. 2015;4:193. https://doi.org/10.4172/2329-891X.1000193.

12. Ethiopia National Expanded Programme on Immunization. Comprehensive multiyear plan, 2016-2020. Addis Ababa: Federal Ministry of Health; 2015.

13. Federal Ministry of Health (FMOH). Revised Health Management Information System (HMIS) Indicator Reference Guide; Technical Standards: Area 1. Addis Ababa: Policy and Planning Directorate; 2017.

14. World Health Organization (2017): Global Health Observatory (GHO) data>measles-containingvaccine first-dose (MCV1) immunization coverage among 1-year-olds. Available at: http://www.who.int/gho/immunization/ measles/en/ [Accessed 26 Feb 2018].

15. Zipprich J, et al. Measles outbreak-California, December 2014-February 2015. MMWR MorbMortal Wkly Rep. 2015;64:153-4.

16. Suijkerbuijk A, et al. Economic costs of measles outbreak in the Netherlands, 2013-2014. Emerg Infect Dis. 2015;21:2067-9.

17. Federal Minstry of Health $(\mathrm{FMOH})$ : Ethiopian growth \& transformation plan, $2010-2015$.

18. Ethiopian Public Health Institute (EPHI), Federal Ministery of Health (FMOH), and World Health Organization (WHO). Ethiopia Services Availability and Readiness Assessment (ESARA) 2016: Summary Report. Addis Ababa: EPHI; 2017.

19. Central Statistical Agency (CSA) [Ethiopia] and ICF. Ethiopia demographic and health survey 2016. Addis Ababa and Rockville: CSA and ICF; 2016.

20. Ketsala $A$, et al, Spatial distribution of under immunization among children 12-23 months old in butajira, Southern Ethiopia, 2016. Unpublished Article.

21. Kulldorff M.(2018). SaTScanTM user guide for version 9.6, 2018. http:// www.satscan.org/.

22. Federal Ministery of Health $(\mathrm{FMOH})$ : Immunization in practice national guideline for health workers, modules for health workers, 2014.

23. Kulldorff M, and Information Management Services, Inc. SaTScan ${ }^{\mathrm{TM}}$ v9.6: Software for the spatial and space-time scan statistics. [www.satscan.org], 2018. 
24. StataCrop. Stata statistical software: release 14. College Station: StataCrop LP; 2015

25. Anselin L, Getis A. Spatial statistical analysis and geographic information systems. Ann Reg Sci. 1992;26(1):19-33.

26. Bernoulli D. Discrete Poisson and continuous Poisson models. In: Kulldorff M, editor. A spatial scan statistic. Communications in Statistics: theory and methods, vol. 26; 1997. p. 1481-96. [https://www.satscan. org/papers/k-cstm1997.pdf].

27. Merlo J, et al. A brief conceptual tutorial of multilevel analysis in social epidemiology: using measures of clustering in multilevel logistic regression to investigate contextual phenomena. J Epidemiol Community Health. 2006;60(4):290-7.

28. Austin PC, Stryhn H, Leckie G, Merlo J. Measures of clustering and heterogeneity in multilevel Poisson regression analyses of rates/count data. Stat Med. 2018;37:572-89. https://doi.org/10.1002/sim.7532.

29. Halonen $\mathrm{J}$, et al. Quantifying neighbourhood socioeconomic effects in clustering of behaviour-related risk factors: a multilevel analysis. PLoS One. 2012;7(3):e32937.

30. Gottschalk R. The macroeconomic policy content of the PRSPs: how much pro-growth, how much pro-poor? Brighton: Institute of Development Studies, University of Sussex; 2004.

31. Ministry of Health and Population/Egypt, El-Zanaty and Associates/Egypt and ICF International. Egypt demographic and health survey 2014. Cairo: Ministry of Health and Population and ICF International; 2015.

32. Kenya National Bureau of Statistics, Ministry of Health/Kenya, National AIDS Control Council/Kenya, Kenya Medical Research Institute, National Council for Population and Development/Kenya, and ICF International. Kenya demographic and health survey 2014. Rockville: Kenya National Bureau of Statistics, Ministry of Health/Kenya, National AIDS Control Council/Kenya, Kenya Medical Research Institute, National Council for Population and Development/Kenya, and ICF International; 2015.

33. National Institute of Statistics of Rwanda (NISR) [Rwanda], Ministry of Health (MOH) [Rwanda], and ICF International. Rwanda demographic and health survey 2014-15. Rockville: NISR, MOH, and ICF International; 2015.

34. Ghana Statistical Service - GSS, Ghana Health Service - GHS, and ICF International. Ghana demographic and health survey 2014. Rockville: GSS, GHS, and ICF International; 2015.

35. Zimbabwe National Statistics Agency and ICF International. Zimbabwe demographic and health survey 2015: final report. Rockville: Zimbabwe National Statistics Agency (ZIMSTAT) and ICF International; 2016.

36. Uganda Bureau of Statistics - UBOS and ICF. Uganda demographic and health survey 2016. Kampala and Rockville: UBOS and ICF; 2018.

37. JSI Research and Training Institute Inc./ The Last Ten Kilo Meters (L10K) Project. Extended program on immunization (EPI) coverage in selected Ethiopian zones: a baseline survey for L10K's routine immunization improvement initiative. Addis Ababa: JSI-L10K; 2015. Availabe at: 110k.jsi. com/Resources/Docs/EPI-baseline-report.pdf.

38. Federal Democratic Republic of Ethiopia, Ministry of Health: Health sector transformation plan-HSTP, July 2015-June 2020 (EFY 2008-2012), 2015.

39. WHO|Measles Surveillance Data. (2016). Available at: http://www.who.int/ immunization/monitoring_surveillance/burden/vpd/surveillance_type/ active/measles_monthlydata/en/ (Accessed 26 Feb 2018).

40. Ernst K, Jacobs ET. Implications of philosophical and personal belief exemptions on re-emergence of vaccine-preventable disease: the role of spatial clustering in under-vaccination. Hum Vaccin Immunother. 2012;8(6): 838-41. https://doi.org/10.4161/hv.19743.

41. Takahashi $\mathrm{S}$, et al. The geography of measles vaccination in the African Great Lakes region. Nat Commun. 2017;8:15585.

42. Abadura SA, et al. Individual and community level determinants of childhood full immunization in Ethiopia: a multilevel analysis. BMC Public Health. 2015:15:972.

43. Acharya P, et al. Individual- and community-level determinants of child immunization in the Democratic Republic of Congo: a multilevel analysis. PLoS One. 2018;13(8):e0202742.

44. Périnet S, Kiely M, De Serres G, Gilbert NL. Delayed measles vaccination of toddlers in Canada: associated socio-demographic factors and parental knowledge, attitudes and beliefs. Hum Vaccin Immunother. 2018. https:// doi.org/10.1080/21645515.2017.1412899

45. Etana B, Deressa W. Factors associated with complete immunization coverage in children aged 12-23 months in ambo Woreda, Central Ethiopia. BMC Public Health. 2012;12:566

46. Kumar D, Aggarwal A, Gomber S. Immunization status of children admitted to a tertiary-care hospital of North India: reasons for partial immunization or non-immunization. J Health Popul Nutr. 2010:28(3):300-4.
47. Shrivastwa N, et al. Predictors of vaccination in India for children aged 12-36 months. Am J Prev Med. 2015:49(6 Suppl 4):S435-44.

48. Wiysonge CS, et al. Individual and contextual factors associated with low childhood immunisation coverage in sub-Saharan Africa: a multilevel analysis. PLoS One. 2012;7(5):e37905.

49. Olorunsaiye $\mathrm{CZ}$, Degge $\mathrm{H}$. Variations in the uptake of routine immunization in Nigeria: examining determinants of inequitable access. Global Health Commun. 2016;2(1):19-29.

50. Fatiregun AA, Okoro AO. Maternal determinants of complete child immunization among children aged 12-23 months in a southern district of Nigeria. Vaccine. 2012;30(4):730-6.

51. Maina LC, Karanja S, Kombich J. Immunization coverage and its determinants among children aged $12-23$ months in a peri-urban area of Kenya. Pan Afr Med J. 2013;14:3.

52. Phukan RK, Barman MP, Mahanta J. Factors associated with immunization coverage of children in Assam, India: over the first year of life. J Trop Pediatr. 2009;55(4):249-52.

53. Govindasamy P, Ramesh B. Maternal education and the utilization of maternal and child health services in India; 1997.

54. Vikram K, Vanneman R, Desai S. Linkages between maternal education and childhood immunization in India. Soc Sci Med. 2012;75(2):331-9.

55. Ibnouf A, Vanden B, Maarse J. Factors influencing immunization coverage among children under five years of age in Khartoum state, Sudan: University of Maastricht. S Afr Fam Pract. 2007:49(8):14.

56. Roy SG. Risk F actors for Childhood Immunization Incompletion in Ethiopia. In: Public Health Theses: Georgia State University; 2010. Paper 90. Available from: http://digitalarchive.gsu.edu/iph_theses/90.

57. Kidane T, Yigzaw A, Sahilemariam Y, Bulto T, Mengistu H, Malay T, et al. National EPI coverage survey report in Ethiopia, 2006. Ethiop J Health Dev. 2008;22(2):148-57.

58. Mathew JL. Inequality in childhood immunization in India: a systematic review. Indian Pediatr. 2012;49:203-23.

59. Aremu O, Lawoko S, Dalal K. Childhood vitamin a capsule supplementation coverage in Nigeria: a multilevel analysis of geographic and socioeconomic inequities. ScientificWorldJournal. 2010;10:1901-14.

60. Brownwright TK, Dodson ZM, van Panhuis WG. Spatial clustering of measles vaccination coverage among children in sub-Saharan Africa. BMC Public Health. 2017;17(1):957.

\section{Publisher's Note}

Springer Nature remains neutral with regard to jurisdictional claims in published maps and institutional affiliations.

Ready to submit your research? Choose BMC and benefit from:

- fast, convenient online submission

- thorough peer review by experienced researchers in your field

- rapid publication on acceptance

- support for research data, including large and complex data types

- gold Open Access which fosters wider collaboration and increased citations

- maximum visibility for your research: over $100 \mathrm{M}$ website views per year

At $\mathrm{BMC}$, research is always in progress.

Learn more biomedcentral.com/submission 